\title{
Fontes de autoeficácia e atividades experimentais de física: um estudo exploratório
}

\author{
Self-efficacy sources and experimental physics activities: an exploratory study

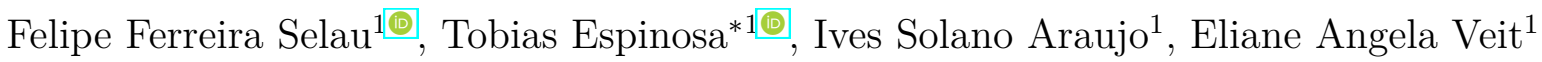 \\ ${ }^{1}$ Universidade Federal do Rio Grande do Sul, Instituto de Física, Porto Alegre, RS, Brasil
}

Recebido em 21 de Junho, 2018. Revisado em 13 de Agosto, 2018. Aceito em 20 de Agosto, 2018.

\begin{abstract}
Parte da comunidade de pesquisa em ensino de Física tem devotado atenção ao estudo de métodos ativos de ensino. Além da aprendizagem dos conteúdos, tais métodos buscam desenvolver habilidades associadas ao trabalho colaborativo e à argumentação. Contudo, o sucesso de tais iniciativas depende, entre outros fatores, do quanto os alunos se julgam capazes de realizar as atividades propostas pelo professor, ou seja, do nível de autoeficácia dos alunos em realizar determinadas ações. Nesse contexto, realizamos um estudo exploratório com o objetivo de analisar os impactos do método Episódios de Modelagem sobre as crenças de autoeficácia discente em aprender física, realizar atividades experimentais e trabalhar colaborativamente. Os resultados apontaram melhoras nos níveis de autoeficácia devido às experiências positivas, observações dos colegas e feedback dado pelo professor.

Palavras-chave: Atividade experimental, crenças de autoeficácia, episódios de modelagem, trabalho colaborativo, ensino de física.
\end{abstract}

Part of the Physics Education Research (PER) community has devoted its attention to the study of Active and Flipped Learning methods. Beyond learning, these methods seek to foster the development of collaborative work and argumentation skill, and also to decrease student's dropout rates. In experimental physics courses, some of those methods involve the scientific modeling learning (e.g., Modeling Instruction (MI) and Modeling Episodes $(\mathrm{ME})$ ). However, the success of such initiatives depends on how students judge themselves capable of carrying out the activities proposed by the teacher, that is, it depends on the student's self-efficacy in perform certain actions. Therefore, we propose a case-study with the purpose of analyze the impact of the ME on the students' self-efficacy beliefs about learning physics; conduct experimental activities; and work collaboratively. The results indicate positive changes in students' self-efficacy due to positive experiences, observation of the classmates, and teacher feedback.

Keywords: Experimental activities, self-efficacy beliefs, modeling episodes, collaborative work, physics education.

\section{Introdução}

Tendo em vista a necessidade de ressignificar as aulas experimentais para irem além da execução algorítmica de procedimentos de coleta de dados, surgem na literatura trabalhos com propostas baseadas no desenvolvimento de aprendizagem por modelagem científica. Em particular, destacamos as propostas dos métodos de ensino denominados Ciclos de Modelagem [1], Modeling Instruction [2] e Episódios de Modelagem (EM) [3], que permitem uma reestruturação na forma de ensinar concedendo ao aluno um papel mais ativo no processo de ensino-aprendizagem. Esses métodos têm por objetivo auxiliar os estudantes a conectarem teoria e prática, e promover o trabalho colaborativo de forma mais autônoma. O método Episódios de Modelagem (EM) foi desenvolvido no contexto da disciplina de Física Experimental II - A do Instituto de Física da Universidade Federal do Rio Grande do Sul (UFRGS) visando a reestruturação dessa disciplina.

*Endereço de correspondência: tobiasesp@gmail.com
Heidemann [4] destaca que os EM promovem crenças e atitudes positivas dos alunos em relação às atividades experimentais, possibilitando que construam concepções adequadas acerca do processo de modelagem científica.

Além dos resultados destacados e da necessidade de reconectar de forma significativa para o aluno atividades teóricas e experimentais, é possível elencar pelo menos outra razão importante para o emprego de métodos ativos: evitar que os estudantes desistam das disciplinas frente aos desafios encontrados. As falhas na compreensão de conceitos básicos de Física Geral e o consequente malogro em provas e testes avaliativos fazem com que os estudantes passem a questionar suas próprias capacidades intelectivas. Fontes e Azzi [5] destacam que as percepções sobre a capacidade de organizar e executar determinado curso de ação são consideradas elementos centrais na motivação e resiliência do sujeito. Tais percepções foram estudadas por Bandura [6-7], que as denominou crenças de autoeficácia, e estão no núcleo fundamental da Teoria Social Cognitiva (TSC). Essas crenças indicam como 
o indivíduo julga suas próprias habilidades em realizar determinada tarefa e influenciam diretamente na persistência do sujeito em enfrentar problemas e situações desafiadoras. Outros trabalhos presentes na literatura apontam que as crenças de autoeficácia são importantes por prever performance, engajamento, retenção e sucesso acadêmico [8-13]. Fencl e Schell [10] sugerem ainda que estratégias de ensino têm efeitos significativos nas crenças de autoeficácia dos estudantes por proporcionarem situações que servem como fontes de autoeficácia. Segundo Bandura [6, 7] as crenças de autoeficácia são afetadas por quatro principais fontes: experiências pessoais, experiências vicárias, persuasão social e estado fisiológico.

Em trabalhos na área de Ensino de Física, a autoeficácia vem sendo investigada, principalmente: na formação acadêmica de alunos e futuros professores [e.g. 14, 15, 16, 17]; em questões de diversidade cultural, étnica, racial e de gênero [e.g. 18, 19, 20]; e de métodos ativos de ensino $[21,22,23]$. Com relação às pesquisas acerca de métodos ativos de ensino, os autores se preocupam em estabelecer relações entre a percepção de autoeficácia e outros diferentes construtos. Poucos estudam como essas crenças se desenvolvem ou fazem uma análise profunda dos fatores que as modificam.

$\mathrm{Na}$ presente pesquisa buscamos investigar, de maneira exploratória, como a implementação do método ativo de ensino EM na disciplina de Física Experimental II A do Instituto de Física da UFRGS influencia as crenças de autoeficácia discente em aprender física, realizar atividade experimental e trabalhar colaborativamente.

Nos Episódios de Modelagem os estudantes dispõem de guias de atividades que problematizam a situação a ser enfrentada; apresentam de forma sucinta alguns dos conceitos científicos relevantes para a compreensão do problema a ser investigado e sugerem algumas alternativas de investigações experimentais que podem contribuir para que o aluno avance no sentido de resolver o problema proposto. Esses guias foram construídos de forma a não tornar a atividade mecânica, como costumam ser as atividades baseadas nos tradicionais roteiros rigidamente estruturados [4]. Entretanto, Heidemann frisa em seus estudos que os alunos apresentaram dificuldades para relembrar, discutir e por em prática os conteúdos necessários para o desenvolvimento da tarefa, mesmo com guias de atividades. Para contornar esse obstáculo, o autor agregou ao método EM as Tarefas de Leitura (TL) do chamado "Ensino sob Medida" (EsM) [24], visando a mobilização prévia de conhecimentos necessários para a solução do problema a ser enfrentado. Nessas tarefas são indicados aos alunos materiais para estudo prévio (e.g. seções de um livro didático) e um conjunto de três a quatro questões a serem respondidas até cerca de $24 \mathrm{~h}$ antes da próxima aula e enviadas eletronicamente ao professor. Na primeira atividade presencial de um Episódio de Modelagem, o professor discute as respostas fornecidas pelos alunos e as principais dúvidas apresentadas nas TL. Em grande parte das aulas são os discentes, trabalhando em pequenos grupos, que delineiam o experimento, coletam os dados e os analisam. Ao final, apresentam os resultados das investigações para o grande grupo.

Para conduzir este estudo exploratório, partimos da seguinte questão norteadora:

Que fontes de autoeficácia, em relação a aprender física, realizar atividades experimentais e trabalhar colaborativamente, são fomentadas em atividades experimentais realizadas com o método ativo Episódios de Modelagem?

Nas próximas seções, apresentamos o conceito de autoeficácia, a metodologia de pesquisa, os resultados e as conclusões do estudo.

\section{Crenças de autoeficácia}

A Teoria Social Cognitiva (TSC), desenvolvida pelo psicólogo canadense Albert Bandura, fundamenta-se no conceito de agência humana (human agency), o que significa que os indivíduos são protagonistas da própria existência, não apenas produtos de condições ambientais. As pessoas são auto-organizadas, proativas, autorreguladas e autorreflexivas [25].

Dentre os mecanismos que compreendem a agência humana, as crenças de autoeficácia assumem, segundo Bandura [7], papel central. Essas crenças são julgamentos que os indivíduos fazem acerca das próprias capacidades de organizar e realizar cursos de ações específicas, e influenciam na maneira como o indivíduo pensa e age nos ambientes sociais de que faz parte. Pajares e Olaz [26] destacam que essas crenças são a base para a motivação humana. "O nível de motivação, os estados afetivos e as ações das pessoas baseiam-se mais no que elas acreditam do que no que é objetivamente verdadeiro" [7, p. 2].

As pessoas com altos níveis de autoeficácia encaram tarefas difíceis como desafios a serem enfrentados; esforçamse mais e são resilientes. Consequentemente, tais crenças influenciam nas decisões que as pessoas tomam no decorrer da vida, fazendo com que escolham, geralmente, caminhos que as levam a exercer ações que se consideram capazes, e evitar ações que se julgam incapazes. É de suma importância que os estudantes se sintam capazes de exercer as ações escolares. Logo, é importante que a escola fomente o desenvolvimento de tais crenças.

Segundo Bandura [7], existem quatro principais fontes de autoeficácia: (i) as experiências pessoais; (ii) as experiências vicárias; (iii) a persuasão social; e (iv) os estados fisiológicos. A maneira pela qual o indivíduo interpreta os acontecimentos de sua vida, fundamenta suas crenças de eficácia pessoal.

(i) Experiências pessoais: os indivíduos interpretam suas experiências anteriores e, com base nessas interpretações, constroem seus julgamentos de eficácia pessoal. Experiências vistas como positivas servem como indicador de capacidade, e experiências interpretadas como negativas indicam incapacidade. Como agente, o sujeito antecipa suas ações com base nas experiências passadas. Bandura [7] destaca que a experiência pessoal (positiva e 
negativa) é a principal fonte de autoeficácia. Ou seja, as pessoas se julgam capazes ou não de exercer determinada ação baseadas mais em suas experiências anteriores do que em qualquer outra coisa. Nesse sentido, propiciar experiências positivas é essencial dentro de uma aula de física.

(ii) Experiências vicárias: as pessoas constroem julgamentos acerca das próprias capacidades por meio da observação de modelos (não físicos, mas sociais). Observar alguém que o sujeito julga como semelhante executando determinada ação pode fazer com que esse sujeito se sinta capaz de fazer o mesmo. Observar um colega resolvendo um problema de física, por exemplo, pode fazer com que o aluno também se sinta capaz de resolvê-lo. Apesar de ser considerada uma fonte mais fraca - comparada à experiência pessoal - a experiência vicária é importante na construção do julgamento de eficácia pessoal em relação às ações ainda não vivenciadas ativamente pelo sujeito. Uma pessoa que nunca dirigiu um carro julgará sua eficácia em dirigir a partir dos modelos sociais que conhece. Em uma aula de física, por exemplo, é incomum que os alunos trabalhem de forma colaborativa para resolver um problema, sendo que alguns alunos podem passar toda sua vida acadêmica sem precisar realizar ações ligadas a esse domínio. Nesse sentido, observar os colegas que já têm certa experiência em trabalhar colaborativamente em ação pode ajudar o sujeito no desenvolvimento de suas crenças de autoeficácia em trabalhar colaborativamente.

(iii) Persuasão social: os indivíduos também criam e desenvolvem crenças de autoeficácia por meio de incentivos dos outros, que podem ser feitos de forma verbal ou não verbal. Além disso, o ambiente social pode persuadir o sujeito de que ele é, ou não é, capaz de realizar determinado conjunto de ações. A fala e o comportamento do professor podem influenciar na autoeficácia percebida pelos alunos. Professores desmotivados, por exemplo, podem reduzir a autoeficácia dos estudantes em ações acadêmicas. O "clima" em sala de aula também pode influenciar; um ambiente de competitividade e individualidade pode ser prejudicial para a eficácia pessoal, enquanto que um ambiente colaborativo pode ser benéfico.

(iv) Indicadores fisiológicos: ansiedade, estresse, dores são reações do organismo que um indivíduo pode sentir ao enfrentar situações ameaçadoras. Tais estados fisiológicos podem ser interpretados pelo sujeito como falta de capacidade em executar determinado curso de ação. Notemos que as reações não são tão importantes, mas sim como o indivíduo as interpreta. A pressão psicológica advinda de uma prova de física, ou do discurso docente, pode desencadear uma série de reações fisiológicas que o indivíduo interpreta como incapacidade. A promoção do bem-estar, por meio de apoio docente, dos colegas e variações na forma de avaliação podem afetar positivamente o desenvolvimento de crenças de autoeficácia em ações acadêmicas.
Na seção seguinte, apresentamos a metodologia de pesquisa que nos permitiu aferir os níveis de autoeficácia e as fontes provenientes de uma abordagem didática com o método Episódios de Modelagem.

\section{Metodologia de pesquisa}

Na concepção de Yin [27] o estudo de caso se destina a pesquisas que almejam estudar os fenômenos sociais de forma mais profunda e geralmente propõe-se a responder questões do tipo "como?" e "por que?". Segundo Yin, o estudo de caso pode ser dividido em três tipos: Exploratório, Descritivo e Explanatório. O exploratório visa produzir novas perspectivas para pesquisas futuras e não exige a elaboração prévia de proposições teórica. Além disso, os casos podem ser do tipo único ou múltiplos. Ambos podem conter mais de uma unidade de análise (estudo de caso incorporado).

Realizamos um estudo de caso do tipo exploratório, único e incorporado com múltiplas unidades de análise. Nosso caso foi uma turma da disciplina de "Física Experimental II - A", e os alunos que vivenciaram os EM constituíram as unidades de análise. Optamos por essa disciplina porque nela foi desenvolvido o método Episódios de Modelagem por Heidemann [4] e também porque essa é uma disciplina obrigatória de todas as ênfases do curso de Física (Astrofísica, Física Computacional, Materiais e Nanotecnologia, Pesquisa Básica e Licenciatura) da Universidade Federal do Rio Grande do Sul (UFRGS).

A disciplina foi ofertada no primeiro semestre de 2016, ao longo de dezenove semanas com um encontro semanal de duas horas-aula de duração. O semestre iniciou com oito alunos (quatro mulheres e quatro homens) e terminou com sete alunos. Uma aluna abandonou a disciplina na décima primeira semana por razões pessoais. A idade dos alunos estava entre 18 e 26 anos, sendo a média em torno de 20 anos. Dos oito estudantes, um cursava licenciatura em Física e os demais estavam divididos nas seguintes ênfases do curso de bacharelado: Astrofísica $(\mathrm{n}=4)$, Materiais e Nanotecnologia $(\mathrm{n}=2)$ e Pesquisa Básica $(\mathrm{n}=1)$. Todos os alunos cursavam a disciplina de "Física Experimental II - A" pela primeira vez. A turma descrita constitui em um caso representativo no contexto de ensino de laboratório da UFRGS.

Os alunos realizaram: quatro Episódios de Modelagem em um total de onze encontros; e cinco experimentos ditos tradicionais (Balança de Cavendish, medida do calor latente de evaporação do nitrogênio líquido, ondas estacionárias, transformações adiabáticas e motores térmicos), ao longo dos outros oito encontros. Para cada atividade dos EM foram solicitadas leituras prévias sobre os assuntos a serem tratados nas aulas por meio das denominadas Tarefas de Leitura (TL). Nos encontros presenciais os estudantes realizavam o planejamento, montagem, coleta de dados e apresentação dos resultados obtidos. Durante todo o processo, a professora auxiliou os grupos questionando e esclarecendo dúvidas sobre os 
modelos teóricos, montagens e coleta de dados. O primeiro autor do presente trabalho atuou como monitor e observador participante durante todo o semestre. Foram elaborados seis relatórios ao longo da disciplina, sendo quatro sobre os episódios de modelagem e dois para as atividades experimentais tradicionais.

Para a nossa pesquisa, a coleta e análise dos dados foram realizadas por meio de uma triangulação entre dados obtidos com dois questionários, entrevistas semiestruturadas e observação participante. O primeiro questionário foi aplicado na primeira semana após o primeiro encontro presencial e o segundo na décima sexta semana, depois de encerrado o último Episódio de Modelagem. Esses questionários visaram determinar os níveis das crenças de autoeficácia dos estudantes em relação a três eixos: aprender física, realizar atividades experimentais e trabalhar colaborativamente. No segundo questionário, os alunos eram questionados acerca de suas crenças no início do semestre (teste retrospectivo) e no final (pós-teste). Os resultados dos questionários, bem como a análise comparativa entre o pré-teste e o teste retrospectivo, podem ser acessados em Espinosa et al. [28]. De acordo com a análise dos autores, o teste retrospectivo representa uma análise mais fidedigna dos níveis de autoeficácia inicial, afinal, como a experiência com o método ativo (Episódios de Modelagem) é nova para todos os alunos, eles não têm conhecimento suficiente de todas as ações requeridas no método, o que os impossibilita de realizarem uma avaliação precisa das próprias capacidades. Esse resultado é corroborado por outros autores que avaliaram a autoeficácia em ensinar ciências de professores em formação que nunca tinham lecionado [29, 30, 31]. Esses professores, assim como os alunos do nosso estudo, superestimaram suas capacidades e, no decorrer da experiência, reajustaram seus níveis de autoeficácia para algo mais próximo da realidade.
As respostas dos alunos aos questionários e os dados coletados no caderno de observação constituíram o ponto de partida para a definição de perguntas específicas a serem feitas a cada estudante, em adição (ou em adaptação) às perguntas da entrevista semiestruturada. $\mathrm{O}$ roteiro de entrevista era composto pelas seguintes questões:

1) De modo geral, comente um pouco sobre a sua experiência na disciplina de Física Experimental II.

2) De modo geral, fale sobre a sua experiência com o trabalho em grupo durante a disciplina.

3) Nos questionários, você mostrou uma variação em suas crenças na capacidade de aprender física, realizar atividades experimentais e em trabalhar colaborativamente. Cite possíveis fatores e/ou situações que contribuíram para essa variação.

As questões 1 e 2 permitiram que os entrevistados contassem suas experiências, mostrando como as interpretaram, o que possibilitou a identificação de fontes de autoeficácia. A última questão, de forma mais direta, perguntava aos alunos as situações e os fatores que, na opinião deles, foram responsáveis pelas modificações nos níveis de autoeficácia. Pajares e Olaz [26] destacam que as fontes de informação de autoeficácia não são apenas avaliações de competências, são as interpretações que os indivíduos fazem acerca dos acontecimentos.

Esses dados foram analisados segundo a metodologia de Robert Yin [32] que recomenda a análise em cinco etapas: compilação dos dados coletados, desagrupamento em fragmentos menores (categorizados ou não) tendo em vista facilitar a análise, reagrupamento em categorias, interpretação das categorias em forma de narrativa e conclusão. Esse processo de análise realizado não é linear.

Para avaliar a ocorrência nos argumentos dos alunos das principais fontes de autoeficácia propostas por Bandura [7] nos orientamos no guia para identificar fontes de autoeficácia desenvolvido por Brand e Wilkins [33]. Uma adaptação desse guia é apresentada no Quadro 1,

Quadro 1: Guia para identificar o surgimento de crenças de autoeficácia.

\begin{tabular}{|c|c|}
\hline Fonte de autoeficácia & Descrição/Evidência \\
\hline Experiências positivas & $\begin{array}{l}\text { São experiências pessoais de sucesso, vivenciadas pelos estudantes através de participação ativa. Esse sucesso } \\
\text { não se refere a resultados comumente ou facilmente atingíveis, mas a conquistas adquiridas através de um } \\
\text { real envolvimento e, até mesmo, superando dificuldades. } \\
\text { Declarações dos estudantes relacionadas às experiências pessoais em atividades específicas da disciplina. }\end{array}$ \\
\hline Experiências vicárias & $\begin{array}{l}\text { São experiências nas quais o indivíduo se inspira pelo sucesso de outra pessoa, que ele identifica como } \\
\text { semelhante. } \\
\text { Afirmações dos alunos que ressaltam a importância das experiências em grupo, como as discussões. }\end{array}$ \\
\hline Persuasão social & $\begin{array}{l}\text { É caracterizada pelo incentivo e apoio, que pode ocorrer através de expressões verbais e não verbais (e.g. o } \\
\text { discurso e o comportamento do professor) e apoio do ambiente (e.g. estrutura e "clima" da sala de aula e } \\
\text { estrutura do método de ensino empregado). } \\
\text { Declarações dos alunos que indicam um sentimento positivo em relação à estrutura do método, ao "clima" e } \\
\text { relações interpessoais em sala de aula e a pronunciamentos do professor. }\end{array}$ \\
\hline Redução de estresse & $\begin{array}{l}\text { É caracterizada pela redução ou eliminação de obstáculos emocionais que poderiam ser percebidos como } \\
\text { incapacidade de realização de uma ação. } \\
\text { Argumentos relacionados à redução de ansiedade ou medo oriundos do método de ensino ou experiências } \\
\text { passadas. }\end{array}$ \\
\hline
\end{tabular}

Fonte - Adaptado de Brand e Wilkins [33]. 
onde especificamos, para cada fonte de autoeficácia, a descrição de Brand e Wilkins [33] e inserimos o que consideramos como evidência de fonte de autoeficácia. A análise é discutida nas subseções seguintes.

$\mathrm{Na}$ próxima seção apresentamos a categorização e interpretação dos dados.

\section{Resultados e discussões}

Que fontes de autoeficácia, em relação a aprender física, realizar atividade experimental e trabalhar colaborativamente, são fomentadas em atividades experimentais realizadas com o método ativo Episódios de Modelagem?

Verificamos, em trabalho anterior, um acréscimo nos níveis de autoeficácia em aprender física, trabalhar colaborativamente e realizar atividade experimental em todos os estudantes que concluíram a disciplina [28]. No presente trabalho, a partir de uma análise qualitativa, identificamos alguns fatores que contribuíram para a mudança nas crenças de autoeficácia desses alunos.

\subsection{Autoeficácia em aprender física}

Espinosa et al. [28] mostraram que, por meio de uma análise retrospectiva, houve um aumento nos níveis de autoeficácia percebida dos sete estudantes aprovados na disciplina. Na entrevista, os alunos associaram o aumento com: as experiências pessoais vivenciadas na disciplina (n $=3$ ); o feedback proporcionado pelo professor na correção das tarefas (persuasão social) $(\mathrm{n}=2)$; e o formato do mé- todo, cuja contextualização e aplicação eram enfatizados no discurso da professora (persuasão social) $(\mathrm{n}=1)$. No Quadro 2, apresentamos as respostas desses seis alunos e a fonte de autoeficácia que julgamos ter proporcionado o aumento dos níveis.

Quando questionamos os alunos a que motivos eles atribuíam o aumento nos níveis de autoeficácia em aprender física, três alunos argumentaram que experiências pessoais proporcionadas pela disciplina os levaram a acreditar mais nas próprias capacidades. Como vimos na Seção 2, a experiência pessoal está relacionada às experiências vivenciadas pelos indivíduos, que podem ser positivas ou negativas. Os Episódios de Modelagem requerem participação ativa dos estudantes nas atividades, possibilitando a ocorrência de experiências pessoais que, se bem conduzidas, são positivas. Os seguintes trechos das transcrições ilustram esse ponto: "eu estava conseguindo fazer as coisas, estava acompanhando" (Estudante 1); "As pessoas pensam que não querem fazer isso, mas aí elas conseguem fazer elas meio que se sentem mais incentivada a apresentar coisas e fazer experimentos." (Estudante 2); e "eu fui aprendendo a entender as coisas durante o semestre e percebendo que eu ia ficando cada vez com menos dificuldade." (Estudante 5).

A Estudante 2 também indicou que o estresse (Estado Fisiológico) envolvido nas apresentações de trabalho atuava, para ela, como um indicador de incapacidade. No entanto, a experiência pessoal de sucesso fez com que percebesse que era capaz. Esse resultado é coerente com o argumento de Bandura [7] de que a experiência pessoal

Quadro 2: Trechos das entrevistas semiestruturadas e as possíveis fontes de autoeficácia envolvidas no aumento dos níveis de autoeficácia em aprender física.

\begin{tabular}{|c|c|}
\hline Trecho da entrevista & Fonte de autoeficácia \\
\hline $\begin{array}{l}\text { [...] Foi um choque bem forte para mim no começo, mas depois eu vi que me dediquei e consegui, entẫo } \\
\text { acho que aprendi fisica... aumentou minha capacidade de aprender física. Aos poucos eu vi que estava } \\
\text { conseguindo... eu estava conseguindo fazer as coisas, estava acompanhando... eu estava dentro do que era } \\
\text { esperado pela disciplina. (Estudante } 1 \text { ) }\end{array}$ & Experiências Pessoais \\
\hline $\begin{array}{l}\text { Uma coisa é tu fazer o experimento e deu... faz o relatório. Outra coisa é tu fazer o experimento e ter de } \\
\text { apresentar. Aí eu tinha de pensar como apresentar sem ficar nervoso e com vergonha. No início eu ficava } \\
\text { muito: "Meu Deus do céu, o que vai acontecer!", mas a apresentação foi rápida e normal. Como tu estudou } \\
\text { tu sabe pelo menos um pouquinho do que tem de apresentar. Então eu aconselharia as pessoas a fazer porque } \\
\text { eu acho que tem um crescimento pessoal envolvido nisso. As pessoas pensam que não querem fazer isso, mas } \\
\text { aí elas conseguem fazer elas meio que se sentem mais incentivadas a apresentar coisas e fazer experimentos. } \\
\text { [...] eu acho que eu evolui e foi muito positivo. Eu tenho muito o costume de me subestimar; penso: "Acho } \\
\text { que eu não consigo fazer isso.". Aí eu fico pensando isso até que eu consigo fazer e mudo de pensamento } \\
\text { para: "Então acho que eu consigo fazer isso." Isso é aquele processo construtivo que tu tem. (Estudante 2) }\end{array}$ & Experiências Pessoais \\
\hline $\begin{array}{l}\text { Meu primeiro relatório veio cheio de comentários, foi um baque para mim e... Esses comentários e correções } \\
\text { foram só melhorando minha nota. Isso eu consegui observar ao longo do semestre que foi só subindo e o que } \\
\text { me ajudou nisso aí foram as correçóes e comentários. Se não fosse por eles eu ainda estaria fazendo uns } \\
\text { relatórios como lá do início da Fúsica Experimental } I \text {. (Estudante 3) }\end{array}$ & Persuasão Social \\
\hline $\begin{array}{l}\text { Alguma experiência que contribuiu foi que sempre antes dos experimentos - antes e depois - mais antes, a } \\
\text { professora dava uma introdução do que se tratava o fenômeno e as aplicaçóes, por exemplo, o amortecimento } \\
\text { do carro e o do pêndulo que tinha uma aplicação. Isso contribuiu para aprender Física porque associa a } \\
\text { teoria que tem por trás com alguma coisa do cotidiano, de novo não ficando só nas contas. (Estudante 4) }\end{array}$ & Persuasão social \\
\hline $\begin{array}{l}\text { Eu acho que é mais uma questão de entender as coisas, eu fui aprendendo a entender as coisas durante o } \\
\text { semestre e percebendo que eu ia ficando cada vez com menos dificuldade. (Estudante 5) }\end{array}$ & Experiências Pessoais \\
\hline $\begin{array}{l}{[. .] \text { O que me afetou bastante foi o feedback que a professora falou dos resultados dos meus relatórios e ela }} \\
\text { disse que estavam bons. Eu realmente não achava que estavam tão bons assim. (Estudante 7) }\end{array}$ & Persuasão Social \\
\hline
\end{tabular}

Fonte - Construção dos autores. 
positiva exerce maior influência para o julgamento de eficácia pessoal que as demais fontes.

Os Estudantes 3 e 7 consideraram que houve uma melhora nos níveis de autoeficácia em aprender física devido à avaliação da professora a respeito dos seus trabalhos. Além de fazer comentários nos relatórios dos alunos, a professora utilizava um protocolo de avaliação em que, usando uma escala de três níveis, se manifestava sobre aspectos específicos do relatórid ${ }^{1}$ ao final, ainda, acrescentava um comentário apreciativo geral, ressaltando os aspectos positivos e as maiores deficiências. No dia da entrega dos relatórios corrigidos os alunos se mostravam interessados em compreender que aspectos não estavam bons e como poderiam melhorá-los. Para esses dois alunos a forma de avaliação da professora serviu como fonte de Persuasão Social.

O Estudante 4 destacou a estrutura do método de ensino (Persuasão Social), no qual a professora contextualizava e mostrava aplicações da atividade, no início e no final do episódio de modelagem, como algo importante para a construção de suas crenças de autoeficácia em aprender física.

$\mathrm{Na}$ entrevista buscamos entender o decréscimo apresentado pela Estudante 8. A aluna associou o decréscimo dos níveis de autoeficácia em aprender física ao seu estado de saúde que, devido ao elevado estresse, causado, em parte, pelo excessivo número de disciplinas que estava cursando (oito), foi se agravando ao longo do semestre. A mudança nos Estados Fisiológicos (aumento no estresse), não acompanhada por alguma experiência positiva, parece ter feito com que essa aluna se julgasse menos capaz de realizar as atividades relacionadas à aprendizagem de física. Só detectamos esse caso em que fatores externos à disciplina tiveram efeitos marcantes acerca do nível de autoeficácia.

Identificamos que a evolução nos níveis de autoeficácia apontada por Espinosa et al. [28] tem origem, principalmente, nas Experiências Pessoais positivas proporcionadas pelo processo de aprendizagem por modelagem científica. Espinosa [34], em análise dos efeitos do método ativo Team-Based Learning sobre os níveis de autoeficácia de estudantes inseridos no mesmo contexto do presente estudo, também destacou as experiências pessoais positivas como principal fonte de autoeficácia em aprender física. Também identificamos a fonte de Persuasão Social em três das nossas unidades de análise. Uma delas destacou, assim como seis alunos do estudo de Espinosa [34], a estrutura do método como importante fonte de Persuasão Social na construção da autoeficácia discente em aprender física.

\subsection{Autoeficácia em trabalhar colaborativamente}

Acerca da variação dos níveis de autoeficácia em trabalhar colaborativamente, apresentadas em Espinosa et al.

\footnotetext{
1 Alguns exemplos de aspectos específicos considerados: explicita o arranjo experimental; explicita como o modelo teórico adotado dirigiu a análise dos dados experimentais; apresenta somente conclusões que contam com amparo de evidências experimentais.
}

[28], notamos que, com exceção da Estudante 8, os alunos auferiram aumento nos níveis de autoeficácia entre os escores iniciais e finais. Na entrevista, esses estudantes associaram o aumento com: as situações individuais vivenciadas no trabalho em grupo (experiências pessoais); a interação que tiveram com os colegas de grupo (experiências vicárias); o incentivo dado pela professora e a forma de trabalho do método EM (persuasão social). No Quadro 3, apresentamos as respostas desses seis alunos à entrevista e uma possível classificação da fonte de autoeficácia que tenha proporcionado o aumento dos níveis.

Tanto a Estudante 8 como a Estudante 5 relacionaram as variações dos níveis de autoeficácia em trabalhar colaborativamente, em parte, a problemas de saúde (Estados Fisiológicos). Na entrevista, a Estudante 5 revelou possuir dislexia e por isso não se sentia confiante em apresentar trabalhos, redigir relatórios e expor suas ideias nas discussões em grupo. Mesmo com esse problema, a aluna alega que a comunicação entre ela e seus colegas de grupo foi melhorando ao longo do semestre. Ela acabou por afirmar que seu nível de autoeficácia em trabalhar em grupo se elevou no decorrer da disciplina. Como justificativa dessa evolução, a Estudante 5 disse durante a entrevista:

[...] apesar de eu ter dificuldade em me comunicar, sou uma pessoa que consegue ouvir bastante e consigo entender facilmente os outros. (Estudante 5)

Os Estudantes 4 e 6 justificaram o aumento na autoeficácia em trabalhar colaborativamente pelas experiências pessoais que tiveram no decorrer da disciplina. $\mathrm{O}$ envolvimento ativo nas atividades de grupo fez com que se sentissem mais capazes de realizarem ações voltadas ao trabalho colaborativo. Proporcionar situações nas quais os estudantes se envolvam ativamente é importante para o desenvolvimento da autoeficácia.

Para os Estudantes 3 e 7, a interação com os colegas - observando-os em ação (experiências vicárias) - influenciou no quão capazes se sentiam para realizar ações relacionadas ao trabalho colaborativo. Como destacado por Bandura [7], as experiências vicárias são mais propensas a influenciarem na autoeficácia quando o sujeito percebe aquele que observa como semelhante. Observar o professor realizando uma atividade pode não surtir o mesmo efeito que observar os colegas. Portanto, o trabalho em grupo no método EM tem maiores chances de evocar esse tipo de fonte.

Apesar de ser uma fonte de autoeficácia mais fraca, os sujeitos se tornam mais sensíveis às experiências vicárias quando são demandados a exercerem ações que não estão acostumados [7]. No ensino de física das universidades brasileiras, por exemplo, é usual que os alunos trabalhem em grupos em aulas de laboratório, no entanto, as atividades se resumem, principalmente, à coleta de dados. $\mathrm{Ou}$ seja, os alunos, na maioria das vezes, não assumem compromissos uns com os outros e não precisam agir de forma colaborativa para atingir um objetivo comum. Além disso, 
Quadro 3: Trechos das entrevistas semiestruturadas e as possíveis fontes de autoeficácia envolvidas no aumento dos níveis de autoeficácia em trabalhar colaborativamente.

\begin{tabular}{|c|c|}
\hline Trecho da entrevista & Fonte de autoeficácia \\
\hline $\begin{array}{l}\text { [...] era bastante estimulado o trabalho em grupo [pela professora]. Também tínhamos de discutir no final e } \\
\text { apresentar as coisas. [...] [as atividades em Física Experimental I] não envolviam grandes problemas que a } \\
\text { gente tinha que resolver e procurar uma solução com as outras pessoas do grupo. (Estudante 1) }\end{array}$ & Persuasão Social \\
\hline $\begin{array}{l}\text { Na balança de Cavendish quando todo mundo trabalhou junto em conjunto eu achei bem legal. Nossa turma } \\
\text { era bem quietinha, nós náo conversávamos tanto, mas no final do semestre nós começamos a nos falar. [...] } \\
\text { O apoio do professor é muito importante! [...] não tem como eu produzir tudo o que eu produzi sozinha. } \\
\text { Então, eu acho que tem de trabalhar em conjunto, tem que falar com o outro, tem que falar com o professor, } \\
\text { tem que tirar as dúvidas e tem de estudar também. (Estudante 2) }\end{array}$ & Persuasão Social \\
\hline $\begin{array}{l}\text { Eu indo atrás me ajudou também, me espelhando também no que ela [Estudante 1] fazia. Essa influência } \\
\text { dela foi boa... no sentido dela [Estudante 1] ser organizada e metódica. (Estudante 3) }\end{array}$ & Experiências Vicárias \\
\hline $\begin{array}{l}\text { [...] É justamente por ter mais experimentos que teve mais trabalho em grupo. Na Física [Experimental] I } \\
\text { tinha aulas que era só no quadro aprendendo o que era desvio padrão e desvio padrão da média. Já aqui } \\
\text { tinha muitos experimentos; a gente se envolvia muito mais. (Estudante } 4 \text { ) }\end{array}$ & Experiências Pessoais \\
\hline $\begin{array}{l}\text { [... Eu acho que foi mais baseado na minha evolução, no fato de cada vez ficar mais fácil de entender. } \\
\text { (Estudante 5) }\end{array}$ & Experiências Pessoais \\
\hline $\begin{array}{l}{[\ldots] \text { em geral tenha sido ao fato de eu ter realmente trabalhado bastante em grupo nesse semestre. Isso em si }} \\
\text { já colaborou com o aumento [...] (Estudante } 6 \text { ) }\end{array}$ & Experiências Pessoais \\
\hline $\begin{array}{l}{[. .] \text { quando eu e a Estudante } 5 \text { sentamos pra fazer o planejamento, nisso daí eu vi o quanto é bom tu trabalhar }} \\
\text { em grupo. Porque a visão que a Estudante } 5 \text { tinha de investigar o problema, de levantar algumas questôes } \\
\text { era muito pertinente. Foram coisas que eu não pensei e nisso dai eu vi o quanto pode ser útil trabalhar em } \\
\text { grupo, tu ter a visão da outra pessoa pra te ajudar ali. [...] (Estudante } 7 \text { ) }\end{array}$ & Experiências Vicárias \\
\hline
\end{tabular}

Fonte - Construção dos autores.

são avaliados, quase que exclusivamente, pelo trabalho individual. Ou seja, trabalhar colaborativamente é algo relativamente novo para os alunos do presente estudo. Esse resultado corrobora o encontrado por Espinosa [34] com a experiência com método Team-Based Learning no mesmo contexto institucional.

Por fim, a persuasão social aparece como fonte de autoeficácia em trabalhar colaborativamente para os Estudantes 1 e 2, os quais apontam a professora como incentivadora do trabalho em grupo.

Em nosso estudo, os sete alunos aprovados na disciplina acreditam ter elevado seus níveis de autoeficácia. Ou seja, os Episódios de Modelagem produziram aumento nos níveis de autoeficácia em trabalhar colaborativamente, assim como o estudo de Espinosa [34] mostrou para outro método ativo de ensino, o Team Based Learning. Nossa análise permite-nos identificar três fontes de autoeficácia (Experiências pessoais, Experiências Vicárias e Persuasão Social) como responsáveis pelo aumento dos níveis de autoeficácia em trabalhar colaborativamente.

\subsection{Autoeficácia em realizar atividades experimentais}

Em estudo anterior, Espinosa et al. [28] constataram que o método EM promoveu um aumento nos níveis de autoeficácia em realizar atividade experimental dos sete estudantes aprovados na disciplina (1 a 7). A diferença metodológica entre as disciplinas de Física Experimental I e Física Experimental II (com método ativo EM) foi mencionada por seis alunos como a causa do aumento nos níveis. Contudo, nossos dados não foram suficientes para identificar as fontes de autoeficácia que permitiram essa melhora, visto que os estudantes não lembravam dos eventos específicos que motivaram o aumento.

A Estudante 8, que deixou de frequentar a disciplina, apresentou redução nos níveis das crenças sobre suas próprias capacidades de realizar atividades experimentais. Assim como nas dimensões anteriores, ela atribuiu a redução aos problemas de saúde desenvolvidos (fatores fisiológicos), devido ao grande número de disciplinas (oito) que estava cursando.

Os resultados encontrados em termos de fontes de autoeficácia corroboram o modelo de desenvolvimento de crenças de autoeficácia desenvolvido por Dou et al. [23], no qual os autores argumentam que as experiências em sala de aula facilitam a atuação das três fontes destacadas no nosso estudo: experiências pessoais, vicárias e persuasão social. Nesse modelo, os estados fisiológicos afetam a autoeficácia, mas por fatores externos à sala de aula, como no caso da Estudante 8 que abandonou a disciplina por problemas de saúde e a Estudante $5 \mathrm{com}$ problemas de dislexia. Entretanto, o estudo desenvolvido por Espinosa [34] mostrou que a forma de avaliação influencia no estresse do aluno e consequentemente nos seus níveis de autoeficácia. Nesse sentido, o autor aponta que uma avaliação diversificada - não focada exclusivamente na nota de provas - pode reduzir o estresse dos alunos e contribuir para o aumento dos seus níveis de autoeficácia em aprender física. No presente estudo a avaliação foi bastante diversificada, pois levava em conta não somente os relatórios individuais, mas também a participação no planejamento e execução do experimento, na apresentação dos resultados do grupo ao final de cada EM e nas discussões finais de cada EM. As respostas às Tarefas de Leitura contribuíam na avaliação final como um bônus. 
Se o aluno as fazia, ganhava algum incremento na nota, mas não era penalizado caso não as fizesse.

\section{Considerações finais}

O objetivo deste trabalho foi investigar os impactos nas crenças de autoeficácia em aprender física, realizar atividades experimentais e em trabalhar colaborativamente por meio da aplicação do método ativo de ensino Episódios de Modelagem (EM). Conforme apresentado, o EM tem como foco conectar teoria e prática em atividades de laboratório visando melhorar a aprendizagem de física e desenvolver habilidades de trabalho colaborativo.

Realizamos um estudo de caso exploratório em uma disciplina de Física Experimental na Universidade Federal do Rio Grande do Sul. Por meio desse estudo, buscamos entender como o método de ensino influencia na ascensão das fontes de autoeficácia (experiências pessoais, experiências vicárias, persuasão social e estados fisiológicos) em relação a aprender física, realizar atividade experimental e trabalhar colaborativamente. Coerentemente com a metodologia de estudo de caso exploratório de Yin, que adotamos, concluímos este estudo exploratório levantando novas perspectivas para estudos posteriores.

Como fontes de autoeficácia em aprender física, destacamos o planejamento experimental, a análise dos dados em sala de aula e as apresentações dos resultados, pois proporcionaram experiências pessoais positivas para os alunos; os comentários da professora, presentes nos relatórios, atuaram como persuasão social.

No caso das fontes de autoeficácia em trabalhar colaborativamente, destacamos o estímulo por parte da professora e o ambiente colaborativo no experimento com a Balança de Cavendish ${ }^{2}$ relacionados à persuasão social; e a prática de trabalho em grupo nos planejamentos e na divisão de tarefas proporcionaram experiências pessoais e vicárias.

Não foram identificadas fontes de autoeficácia em realizar atividades experimentais. Conforme já mencionado, nossos dados não foram suficientes para identificá-las nessa dimensão. Essa questão deverá ser revista em estudos futuros.

Com nossos resultados podemos perceber que o método EM não só promove atitudes favoráveis [4], mas também possibilita oportunidades para que três fontes de autoeficácia se manifestem (experiências pessoais, experiências vicárias e persuasão social). Além disso, podemos sugerir que o processo de aprendizagem por modelagem científica está relacionado com essa potencialidade, visto que, o método Modeling Instruction (também baseado nesse tipo de aprendizagem) mostrou o mesmo potencial na promoção de situações que servem de fontes de autoeficácia aos alunos [35, 12, 18, 21, 23].

O presente estudo exploratório, e o estudo realizado por Espinosa [34] investigando o desenvolvimento de fontes de autoeficácia com o método Team-Based Learning em

\footnotetext{
2 Como só dispúnhamos de uma Balança de Cavendish, os oito alunos realizaram o experimento de determinação de G em um único grupo.
}

uma disciplina teórica no mesmo contexto educacional, convergem em alguns pontos, os quais nos permitiram inferir a seguinte proposição teórica:

Episódios de Modelagem propiciam condições para o desenvolvimento de crenças de autoeficácia discente em aprender física, trabalhar colaborativamente e realizar atividades experimentais, por meio das quatro principais fontes: experiências pessoais, experiências vicárias, persuasão social e estados fisiológicos. As experiências pessoais positivas são fomentadas especialmente durante a execução dos experimentos (planejamento, coleta e análise de dados) e nas discussões iniciais e finais. As experiências vicárias são estimuladas durante as atividades em grupo, os quais, criam, ao longo do tempo, um sentimento de confiança mútua entre seus membros que auxilia no desenvolvimento de crenças de autoeficácia nas dimensões avaliadas. Na persuasão social, o professor tem papel central ao fornecer feedback ao estudante acerca do seu trabalho nas tarefas. Além disso, a persuasão social atua na estrutura do método de ensino, que é focado na problematização a partir de situações reais e conceitualização. Por fim, as avaliações diversificadas, não calcadas exclusivamente nos relatórios individuais elaborados pelos alunos, mas que levam em conta o empenho nas respostas às tarefas de leitura e nas discussões iniciais e finais, podem atuar como redutor do estresse. Também a existência de protocolos para a correção de relatórios, devolvidos com comentários aos alunos, contribui para diminuir o estresse dessa avaliação.

Novos estudos, de natureza explanatória, serão conduzidos a fim de explicar e aprofundar a proposição teórica acima.

\section{Agradecimentos}

Ives Solano Araujo agradece ao $\mathrm{CNPq}$ pela bolsa de produtividade em pesquisa concedida.

\section{Referências}

[1] D. Hestenes, in: Girep Conference: Modeling in physics and physics education editado por E. Berg, T. Ellermeijer e O. Slooten (Universidade de Amsterdam, Amsterdam, 2006), p. 34.

[2] E. Brewe, Am. J. Phys. 76, 1155 (2008).

[3] L. A. Heidemann, I. S. Araujo e E.A. Veit, Rev. Bras. Ensino Física 38, 1504 (2016).

[4] L. A. Heidemann, Ressignificação das atividades experimentais no ensino de física por meio do enfoque no processo de modelagem científica. Tese de doutorado em Ensino de Física, Universidade Federal do Rio Grande do Sul, Porto Alegre (2015).

[5] A. P. Fontes e R. G. Azzi, Estud. Psicol. 29, 9 (2012).

[6] A. Bandura, Psychol. Rev. 84, 191 (1977).

[7] A. Bandura, Self-efficacy: the exercise of control (Freeman and Company, New York, 1997).

[8] T. Matsui, K. Matsui, e R. Ohnishi, J. Vocat. Behav. 37, 225 (1990).

[9] S. Andrew, J. Adv. Nurs. 27, 596 (1998).

[10] H. Fencl e K. Schell, J. Coll. Sci. Teach. 35, 20 (2005). 
[11] V. Sawtelle, A Gender Study Investigating Physics SelfEfficacy, disponível em http://digitalcommons.fiu. edu/cgi/viewcontent.cgi?article=1622\&context= etd.

[12] V. Sawtelle, E. Brewe e L. H. Kramer, in Proceedings of the Tenth Annual College of Education $\&$ GSN ResearchConference, Miami, 2011, editado por M.S. Plakhotnik, S.M. Nielsen e D.M. Pane (Florida International University, Miami, 2011), p. 216.

[13] V. Sawtelle e A. Little, in Physics Education Research Conference Proceedings, College Park, 2015, editado por A.D. Churukian, D.L. Jones e L. Ding (American Association of Physics Teachers, College Park, 2015).

[14] G.K. Ferreira e J.F. Custódio, Lat. Am. J. Phys. Educ. 7, 364 (2013).

[15] S. Kapucu e E. Bahçivan, Res. Sci. Technol. Educ. 33, 252 (2015)

[16] D.M. Rocha e E.C. Ricardo, Cad. Bras. Ensino Física 31, 333 (2014).

[17] D.M. Rocha e E.C. Ricardo, Cad. Bras. Ensino Física 33, 223 (2016).

[18] V. Sawtelle, E. Brewe, e L.H. Kramer, J. Res. Sci. Teach. 49, 1096 (2012).

[19] S. Fries-Britt, C.A.G. Mwangi e A.M. Peralta, J. Stud. Aff. Res. Pract. 51, 459 (2014).

[20] J.M. Nissen e J.T. Shemwell, Phys. Rev. Phys. Educ. Res. 12, 020105 (2016).

[21] V. Sawtelle, E. Brewe, R.M. Goertzen e L.H. Kramer, Phys. Rev. Spec. Top. Phys. Educ. Res. 8, (2012).

[22] J.E. Dowd, I. Araujo e E. Mazur, Phys. Rev. Spec. Top. Phys. Educ. Res. 11, 1 (2015).

[23] R. Dou, E. Brewe, J.P. Zwolak, G. Potvin, E.A. Williams e L.H. Kramer, Phys. Rev. Phys. Educ. Res. 12, 020124 (2016).

[24] I.S. Araujo e E. Mazur, Cad. Bras. Ensino Física 30, 362 (2013).

[25] A. Bandura, in Great Minds in Management, editado por G.K Smith e A.M. Hitt (Oxford University Press, Oxford, 2005).

[26] F. Pajares e F. Olaz, in Teoria Social Cognitiva: conceitos básicos, editado por R.G. Azzi, A. Bandura e S.A.J. Polydoro (Artmed, Porto Alegre, 2008).

[27] R. K. Yin, Estudo de caso: planejamento e métodos (Bookman, Porto Alegre, 2010).

[28] T. Espinosa, F.F. Selau, I.S. Araujo e E.A. Veit, Rev. Enseñanza de la Física 29, 7 (2017).

[29] P. Cantrell, Sch. Sci. Math. 103, 177 (2003).

[30] R.P. Hechter, J. Sci. Teacher Educ. 22, 187 (2011).

[31] T.J. Cartwright e J. Atwood, Int. J. Sci. Educ. 36, 2421 (2014).

[32] R.K. Yin, Qualitative Research from Start to Finish (The Guilford Press, New York, 2011).

[33] B.R. Brand e J.L.M. Wilkins, J. Sci. Teacher Educ. 18, 297 (2007).

[34] T. Espinosa, Aprendizagem de Física, Trabalho Colaborativo e Crenças de Autoeficácia: Um Estudo de Caso com o Método Team-Based Learning em uma Disciplina Introdutória de Eletromagnetismo. Dissertação de Mestrado em Ensino de Física, Universidade Federal do Rio Grande do Sul, Porto Alegre (2016).

[35] V. Sawtelle, E. Brewe, e L.H. Kramer, AIP Conf. Proc. 1289, 289 (2010). 